\title{
Can e-Government Applications Contribute to Performance Improvement in Public Administration?
}

\author{
Elias Pimenidis \\ School of Architecture, Computing and Engineering \\ University of East London \\ 4-6 University Way, E16 2RD \\ London, United Kingdom \\ tel: 0044-2082237655 \\ fax: 0044-2082232963 \\ email: e.pimenidis@uel.ac.uk \\ Christos K. Georgiadis* \\ Department of Applied Informatics \\ University of Macedonia \\ 156 Egnatia str. \\ 54006 Thessaloniki, GREECE \\ tel: 0030-2310891869 \\ fax: 0030-2310891202 \\ email: geor@uom.gr
}

\section{Biographical notes}

Dr. Elias Pimenidis has worked in manufacturing for more than ten years before moving to academia and completing a $\mathrm{PhD}$ at the University of Abertay Dundee in the UK. He is a CITP member of the British Computer Society and a Senior Lecturer at the University of East London. His research focuses on risk in developing web-based applications in the area of e-business and e-government, while his most recent endeavours concern the security of web services and its impact on their interoperability. Other work in the area of security includes digital identification and its interoperability across Europe.

Dr. Christos K. Georgiadis is an Assistant Professor at the Department of Applied Informatics, University of Macedonia, Thessaloniki, Greece. He holds a BSc in Mathematics and a PhD in Information Systems Security - Access Control for Web Databases, both from the Aristotle University of Thessaloniki. His research interests include the areas of ecommerce and m-commerce technologies, e-security, and web services supporting technologies. His research has been published in international journals and conference proceedings. He is a professional member of ACM and the SIGEcom, member of the Greek Computer Society and member of the Hellenic Operational Research Society.

* corresponding author 


\title{
Can e-Government Applications Contribute to Performance Improvement in Public Administration?
}

\author{
Elias Pimenidis, University of East London, United Kingdom \\ Christos K. Georgiadis, University of Macedonia, Greece
}

\begin{abstract}
Electronic Government applications have been the focus of hundreds of local and national government administrations all over the world during the past decade. The emphasis of most of these applications lies in their effort to improve the experience of the user in interacting with public administration services and to minimise waiting times in completing transactions public services and citizens. Early applications were relying mainly on the speed and simplicity of submitting a request by the user while most of the work beyond the web based interaction was carried out as in the era before the introduction of the web based applications. The benefits from such endeavours have been short lived as citizens are looking for real enhancements in the way public administration serves their needs and responds to their requests. The authors argue that for e-government applications to succeed, considerable changes in the way public administration organizes itself and how it utilizes information management systems to respond to user / citizen requirements including and addressing the goals of all stakeholders involved are required. Currently the number of successful applications to that end is quite low when compared to the projects implemented and the resources invested in such systems so far. The authors propose steps that would maintain the focus of future implementations in doing so. They also identify the next steps for research in addressing this complex and ever evolving issue.
\end{abstract}

Keywords: electronic government; public administration; stakeholder goals; performance enhancement; e-government evaluation

\section{INTRODUCTION}

Electronic Government applications have been the focus of hundreds of local and national government administrations all over the world during the past two decades. The emphasis of most of these applications lies in their effort to improve the experience of the user in interacting with public administration services and to minimise waiting times in completing transactions public services and citizens.

E-government can be described as an interdisciplinary domain mainly based on Information Communication Technology (ICT) and Public Administration management theory and practice. Electronic government initiatives incorporate Technologies to improve the way government serves citizens and businesses. As such technology, processes and people have to be integrated in its applications.

Early applications were relying mainly on the speed and simplicity of submitting a request by the user while most of the work beyond the web based interaction was carried out manually or more precisely in a human/clerk intensive manner, as in the era before the introduction of the web based applications. The benefits from such endeavours have been short lived as citizens are looking for real enhancements in the way public administration serves their needs and responds to their requests (Athif \& Pimenidis, 2009).

Public Administrations even in the most technologically advanced and developed 
countries have been traditionally conservative in the way they handled citizen transactions. In the current era of the digital information society, the public is becoming increasingly more aware of its rights and its obligations towards public administration and consequently the government. Citizens increasingly demand better value for money from the services they receive and the government in turn is seeking better ways of serving the citizens, knowing well that government accountability is very high in the public's agenda nowadays (Millard, 2010; Kolsaker \& Lee-Kelley, 2009).

Information systems often automate tasks, previously undertaken by humans in an organization, while at the same time removing tasks that are found to be redundant from the organizational point of view or creating new simpler ones. Consequently, in most cases, information systems development and business process reengineering are considered as two views of the same activity that need to be reconciled (Grau, Franch, \& Maiden, 2008). The above is particularly true in electronic government development where implementations should aim at reducing wasteful activities by automating fully structured jobs that can be fully described and specified.

The authors argue that for e-government applications to succeed changes would have to be effected in the way public administration organizes itself and how it utilizes information management systems to respond to user / citizen requirements. This paper reviews case studies where e-government has contributed in changing the way public administration serves citizens, while it discusses the approaches followed in building successful e-government systems that embrace the above philosophy.

\section{E-GOVERNMENT IMPLEMENTATIONS AND EFFICIENCY GAINS}

Most organizations that have implemented or are currently implementing e-government systems are following models that propose starting off with the user / citizen interaction part of the implementation. In doing so, public organizations aim at making the applications attractive to the public expecting to induce users in using the systems frequently (Mousavi, Pimenidis, \& Jahankhani, 2007a; Mousavi, Pimenidis, \& Jahankhani 2007b). This might make the applications appear successful initially, but the authors question the long term value of such systems. Research of e-government applications across the European Union alone shows that a large number of such applications fail quite early. This is usually due to the fact that the organizations that have developed them loose interest in continuing to supporting them utilising resources without getting any real value in return. Most of such applications endup being semi-abandoned information posting spots with sometimes dated information on them (European Commission, 2011). The authors argue the case of every e-government application needing not only to address the interaction with the user / citizen, but to ensure that the systems developed improve the functions, efficiency and performance of the organization that offers the services. In short the organizations need to focus on developing both the front-end as well as the back-office applications if they aim at improving the efficiency and performance of public administration functions and facilities.

The use of decision support and knowledge management systems interacting and exchanging information with web based systems can greatly simplify the process of serving the citizen in structured and semistructured cases of decision making in delivering a service. Speed, accuracy, consistency and integrity of the transactions can be improved to lead to achieving very high levels of efficiency of offering government services online (Pimenidis, Georgiadis, Bako, \& Zorkadis, 2008).

Currently the number of successful applications to that end is quite low when 
compared to the projects implemented so far. The authors propose steps that would maintain the focus of future implementations in doing so. Looking at successful implementation cases and focusing on all stakeholders when planning and designing e-government implementations is a key issue for every country and every public service aiming to achieve value adding e-services. Such services should yield value for both the developers / owners of the service and the users / citizens that would utilize it. Both public administration and the public could have both tangible and intangible benefits to draw upon. Within the context of this work we deal with tangible benefits only and these could be classed as:

a) Savings in time - reduced turnaround time for completing a transaction (public administration and the public)

b) Savings in cost - due to the simplification of the process in back office operations (public administration)

c) Savings in cost - due to reduced need for travelling (the public) and elimination of creation and duplication of paperwork (public administration and the public)

\section{SUCCESSFUL CASES IN E-EFFICIENCY}

Despite the negative tone of the earlier sections of this paper, there are some excellent examples of good practice of e-government applications that have delivered and continue in doing so great value to both the public administration and the citizens. In this section the authors briefly outline the key features of each of them.

Gascó \& Jiménez (2008), discuss the case of the Barcelona City Council. There the existence of a political drive aimed at both the improvement of services and communication to citizens and the attainment of efficiencies and cost savings in the business processes has led to the successful implementation of e- government services that have in turn led to the transformation of the way local government operates and interacts with the public. This transformation was achieved through using e-government design to reconstruct the internal format and the mode of operation of the Barcelona council, by designing totally new services based on the capabilities that ICT could offer.

Administrative reconstruction, Informational accountability, Influence and leadership of Barcelona City Council were the key driving factors that resulted in the improvement of services and communication to citizens and the attainment of efficiencies and cost savings in the business processes.

E-Government adoption in the Barcelona City Council has taken place in waves, conditioned by the characteristics and availability of the technology itself but, chiefly, due to strategic priorities and political leadership. It is that strong leadership that empowered the designers to focus on strategic stakeholders and to provide an enabling administrative infrastructure that has acted as a very powerful change management agent.

In a similar case, driven by political will to improve services, achieve savings in resource utilization and promote sustainability, the London Borough of Havering have implemented e-services that allow their staff to improve the rate of maintenance of buildings and facilities by improving their planning and avoiding duplication of effort and wastage of resources. This has resulted in considerable reduction in the maintenance backlog having achieved a reduction of just over $50 \%$ during the past three years (London Borough of Havering, 2008).

In a rather different case the approach to egovernment development followed its own distinct pathway with equally strong and beneficial results for all involved. Historically the citizens of Dubai would access services by: visiting local or regional offices, paper and postal communications and telephone interactions. The transfer of a service to online 
delivery reduces the demand on the traditional channels and presents the opportunity for savings through reduction in the resources required to support them. Complete closure of a traditional access channel may well be contemplated. Cost benefit assessments such as these depend upon significant assumptions about the number of citizens who will move to an online service delivery channel. This was the key challenge that the Dubai Municipality was facing when they introduced their award winning e-government portal and host of eservices. The success of this particular implementation was largely based on political will by the local authorities to enhance their services through e-provision and their readiness to offer incentives to users to make the uptake attractive than enforced. Care should be taken though, that such incentives are offered with the context of balancing out their costs against perceived and eventually achieved savings (Elnaghi, Elliman, AlShawi, Aziz, \& Kamal, 2008).

The above links well with the case of the UK Inland Revenue service online taxation project. Results had shown that by 2002 a 50\% take up has been achieved with staff savings of 1,300 posts with current figures for usage at $70 \%$ (Elnaghi et al., 2008). In several cases though complete transfer of the service to an electronic based one may not be possible under existing statutory and regulatory frameworks (Notwithstanding European Directives on the validity of electronic signatures) there are still situations where the agency needs to have physical signatures or to be able to inspect physical documents. This prompts the debate about the motivation behind citizen take-up of services and the need to create incentives for citizens to switch to online services. Studies in this area identify a variety of barriers perceived by citizens. These include lack of online experience, trust and visual appeal as well as poor information quality and the degree of stress. However, many of these barriers lead to citizens not even trying to use the service. The extended technology acceptance model highlights the importance of social influences. Hence the need to encourage potential users to try out the technology by creating incentives for citizens is important. However, many of these raise issues of sustainability, appropriate use of public funds and equality of opportunity where citizens cannot gain the benefit through no fault of their own (Irani \& Elliman, 2007; Irani, Elliman, \& Jackson, 2007).

\section{USING STAKEHOLDERS IN THE DESIGN OF SUCCESSFUL E- GOVERNMENT}

Savvas, Pimenidis, \& Sideridis (2007) have classified the public administration services of the fifteen older member states of the EU on the basis of vision and objectives for egovernment, in two dominant trends: a) the empowerment of democracy through an open, transparent and participatory society (social state model) and b) improving on monetary performance through cuts on state expenses or on returns based on raise of competitiveness and on increasing of job offering by businesses. Citizens obtain additional gains through tax reduction (market driven model).

A different classification by Billiets et al. (2006) distinguishes between normative and operational models:

1. A normative model is characterized by increased interest for legal formality. A distinctive type of law, public law, governs the functioning of the state as well as the relations between public entities and civil society. Such PAs are rule oriented mechanisms.

2. Operational administrative systems are result-oriented mechanisms. Legal tools are not ignored, but quantitative methods based on the use of performance indicators, strategic and operational planning, cost-benefit analysis and other similar techniques, mostly borrowed from business management, are the backbone of administrative working methodologies.

In both the above mentioned approaches Southern European countries like Greece, 
Spain, Italy, Portugal, and those of continental Europe like Belgium, France, Luxembourg, Germany, Austria are grouped together in two groups as to the first of the dominant trends identified in the author's previous work.

Within society there are socioeconomic challenges that create needs to citizens and businesses. Such needs are usually addressed by politicians turning them into policy objectives. In response to these objectives, inputs are assigned in the form of resources which by certain processes produce/provide outputs. Under the influence of the environment these outputs produce outcomes (effects and consequences). These respond to existing socioeconomic issues or prevent new ones from arising. Public Administration in its broader sense is where governance as formed by politicians is exercised. Public Organizations' and public servants' tasks are focused on meeting the above governance requirements in the most efficient manner possible. To achieve such efficiency targets all stakeholders involved in delivering and receiving the outcome of a service have to be considered before this is restructured and delivered as an online service.

\section{E-GOV STAKEHOLDERS' DEPENDENCIES}

In an e-government development project all stakeholders that could interact during the eGovernment life cycle are considered. These could include government, public administration officials, society and technology as a whole. Furthermore, both national and supranational authorities are included, with national government goals relating to e-government or public administration modernization and the EU goals to a unified European aspect (Savvas et al., 2007).

In public administration, goals of public organizations (public administration entities) and goals of public servants coexist as entities of an administrative universe of discourse.
Society includes goals from citizens and businesses. Technology is regarded as a stakeholder meaning that scientists that promote research are interested in real world cases and that exploitation of contemporary and documented solutions is a guarantee of success and efficiency.

E-government is a means of adjusting governance to the current socioeconomic requirements. In doing so, the current status of laws and institutions as frameworks in which any e-government initiative should evolve are considered.

Thus e-Gov is the vehicle, which starts as a vision, concept and template from the government and follows the next steps in order to be implemented. In these steps needs and constrains are added. The direct receiver of the political-economical view is public administration. Its procedural nature and its constitutional principles filter through the political-economical vision.

Two additional filters are considered:

A) Societal. This relates to the current status of needs, wills and behaviours of social entities. Citizens and businesses add their specific needs to the template on stocks.

B) Vested technology following current trends and subject to constraints.

Clockwise, technology oriented solutions has been tested, but it is not possible for them to provide working results. For example, for interoperability issues there is the option of the implementation of governmental intranets, but to exploit full dynamics of an interoperable linkage it is better to define involved administrative units and procedures. Additionally interoperability may be restrained by security issues.

Similarly, simply following citizens' and businesses' wills is unwise since public administration also defends constitutional principles and legitimacy that lie beyond these wills. The state serves citizens and businesses through public administration and receives their messages for readjustment politics through various channels. Society cannot 
directly affect procedures that public administration follows. This is the public administration services' managers and executives' privilege.

\section{Stakeholders' Goals}

The following stakeholder requirements have been deduced using formal documentation and surveys.

\section{Current e-Government Strategies in the EU}

Concerning vision and objectives for egovernment in the EU's fifteen older member states, the following two dominant trends have been identified (Savvas et al., 2007):

- The empowerment of democracy through an open, transparent and participatory society (social state model)

- Achieve financial benefits through cuts in state expenses or benefits based on raise of competitiveness and on increase in job offerings by businesses. Citizens obtain additional gains through tax reduction (Market driven model).

Components of the first model are, a) participation and b) transparency, while those of the second model are identified as efficiency, effectiveness and money savings.

\section{EU Goals / Requirements}

E-Government is expected to help public administrations to realise good governance ('egovernance') in terms of an administration that is:

- Open and transparent, i.e. democratic and accountable

- Inclusive, i.e. provides services for all

- Efficient and productive, i.e. provides maximum value for taxpayers' money.

These goals are consistent with those ones mentioned above for the governments of the EU member states. The same, to an extend stands for the new i2010 e-Government Action Plan that defines five priorities (The new European strategy for Information Society i2010):

\section{No citizen left behind}

2. Making efficiency and effectiveness a reality - significantly contributing to high user satisfaction, transparency and accountability.

3. Implementing high-impact key services for citizens and businesses

4. Putting key enablers in place

5. Strengthening participation and democratic decision-making

In addition the European Union focuses in three groups of issues for e-Government beyond 2005:

1. The first set of issues is about the challenge to move towards more profound modernisation of public administrations with the help of ICT, organisational change, and improvement of human resources in public administrations, in order to deliver sustainable benefits.

2. The second set of issues addresses the challenge to achieve innovation in government services and governance in order for public administrations to realise their full potential as key contributors to economic and social development. Governance meaning the rules, processes and behaviour, that affect the way public administration functions.

3. The third perspective focuses on contributing to European e Government Objectives: the emergence of pan-European eGovernment solutions, contributing to a European public asset of e-Government building blocks, implementing European policies and increased cooperation at European level in order to better address e-Government at all levels.

EU goals follow those of national governments because EU guidelines are not mandatory.

\section{Citizen and Business Goals}

Citizen and business requirements are reported in many studies held by various institutions throughout Europe. The majority of these studies are not focused on satisfaction of users but they assess people needs as a means for establishing the right level of services required 
to meet those needs. Generally citizens' requirements are taken into consideration when they are not contradictory with the ones for European citizens. They possibly represent additional functional and technical requirements that have to be taken into consideration.

\section{Technology Goals}

Technology requirements result both from technological evolution and evolution on project management and managerial decisions, related to the use of applicable and sustainable systems. They also refer to cost evaluation and other economical matters. They are also led by scientific and technological progress as identified in best practices cases (Sideridis, Pimenidis, Protopappas, \& Koukouli, 2011).

Electronic government is far more than a lofty, idealistic notion. Nearly every country in the world - from the poorest to the richesthas considered and most have implemented some form of it, and the extensive literature on the subject continues to grow. Considerable evidence suggests that even the most technologically advanced countries aren't getting the full return yet for their egovernment investments with poorer nations fare even worse (Mousavi et al., 2007a; Mousavi et al., 2007b). This is one of the key reasons that e-government implementations need to intensify their focus on applications that reach beyond the plain information dissemination stage.

This paper argues that to get the full return of the e-government investment it is critical to consider all stakeholders and their goals. Satisfying these goals is a sine qua non condition for a project's or an initiative's success. The ability of mapping these goals to stakeholders' goals reveals proper or insufficient provisions, allowing revisions in the early design stages.

A service needs information for a certain goal. This goal is usually placed in the external environment of the organization.
Mapping system's goals to stakeholders' ones could be made through wider goals/strategic objectives like the ones below:

National interoperability standards, exploitation of ICT in promotion of information, access to Internet, simplification of administrative procedures that leads to reduction of administrative cost for businesses therefore to a reduced production cost and raise of competitiveness.

Collaboration between public organizations should lead to the dissemination of such good practices in all regions of public administration and other public organizations that conform to the development law.

\section{EVALUATING E-GOVERNMENT}

There is though an antilog to the whole drive for pure efficiency in terms of operations alone. Currently, e-government systems aim at improving operational efficiency in governance primarily targeting cost-cutting and faster processing of taxes and other income generating activities, ignoring or not focusing in the best of cases on the citizens' needs. One cannot help but asking the question whether governments have the capacity, the interest and the incentive to improve egovernment systems? Only if they really mean to achieve real e-democracy, to fight corruption, to improve the level of services, to minimise citizen life disruption in receiving such services and achieve equality across society will they strive to develop such systems and services to the citizen's advantage.

Web services and the semantic web offer an opportunity for governments to capitalise on existing services and offer citizens the choice of a variety of safe and trusted vehicles through which they can interact with government services. The wider the choice and the wider spread the mediums of delivery of such services they become, the greater the level of inclusivity will be achieved. Infrastructure problems cost of access and 
familiarity with emerging technologies can be overcome if the service is attractive and if it is delivered over a range of access media (Kolsaker \& Lee-Kelley, 2009; Pimenidis, Sideridis, \& Antonopoulou, 2009).

Since the dawn of online services many people believed that the power of ICT alone could drive social change in predictable and desirable ways. The past two decades have supplied many successful examples of egovernment services, but there is at least an equal number of those that demonstrate the triumph of hope over experience in the ability of e-government to drive change. The use of government portals, the shop window of many e-government programs, has on average attracted no more than $30 \%$ of the population, making them appear as either inefficient or in the worst case exposing the rest of the citizens to the risk of the digital divide (Millard, 2010; Pimenidis, Iliadis, \& Georgiadis, 2011).

\section{e-Government Capacity Measurement}

e-Government is promoted as a means of transforming government, empowering the citizens and ushering in a new era of deliberative democracy. In doing so though governments and related agencies do not shift the focus away from technology and towards the social and process reengineering exercises required to empower such services. Instead ICT remain at the core of a country's "world view" of digital services and the ability to improve efficiency, effectiveness and social inclusion and equality.

Since 2000, the Economist Intelligence Unit (EIU) has been assessing the world's largest economies on their ability to absorb ICT and to use it for economic and social benefit. This benchmarking exercise was originally termed the "e-readiness rankings" and has evolved as the definitive guide to a country's potential of delivering technology empowered services. Since 2010 the study has been renamed as the "digital economy rankings", to reflect the increasing influence of ICT in economic (and social) progress. Despite the social element taken into consideration for the first time, the emphasis has not shifted from its technology dominated core. Infrastructure metrics, points of access, telephone landline density are predominant amongst the assessment criteria to rank a country as to its ability to develop and deliver online services. The digital economy rankings assess the quality of a country's ICT infrastructure and the ability of its consumers, businesses and governments to use ICT to their benefit. It is perceived that when a country uses ICT to conduct more of its activities, the economy can become more transparent and efficient. The EIU ranking allows governments to gauge the success of their technology initiatives against those of other countries, while companies that wish to invest or trade internationally can use them as an overview of the world's most promising business locations from an ICT perspective.

The e-government survey conducted by the UN addresses more issues relating to social aspects and targets transparency in government and the involvement of the public in decision making. The survey attempts to benchmark technology used and the relevant investment against the effectiveness of the solutions.

None of the above reports seeks the reasons for failure or slow progress in a country's capacity to reflect the public's / user's requirements into its plans and implementations of government led online service. Instead a blanket assumption that all shareholders would benefit from the implementation of e-government services has been adopted, without investigating whether these reflect actual user needs as these are perceived by the public. This is an issue for further research of how to blend the measures of systemic efficiency gains to those of enhancing the social fabric and promoting society, thus embracing the whole context of a government's duties to its citizens and hence integrating tangible and intangible objectives in the context of evaluating e-government systems and processes. 


\section{CONCLUSIONS}

Despite the widening participation in egovernment projects and implementations, the return from such investments is still quite low even in the most advanced countries in the developed world. To improve the efficiency of such applications, e-government services have to take into consideration all stakeholders' needs at the design stage. In doing so the needs of the citizens as the recipients of the service will be met both directly through savings in time and direct costs, but also indirectly through improved efficiency at the organization delivering the service. This improved efficiency will result in the organization achieving better performance management, saving resources to redirect to other services that might require more and satisfy the need for more sustainable services within the demands for more efficient and accountable governance.

The reader should note though that the sole reliance of a country's effort on improving access to ICT in improving the way the public interacts with the government is a rather flawed approach. The wider the choice and the wider spread of the mediums of delivery of eservices, the greater the level of inclusivity will be achieved and wider inclusivity will yield better interaction and satisfaction.

Problems with infrastructure, cost of access and familiarity with emerging technologies can be overcome if the service is attractive and if it is delivered over a range of access media.

\section{REFERENCES}

Athif, A., \& Pimenidis, E. (2009). E-crime threats on e-government - The case of Maldives. Proceedings of the 4th Advances in Computing and Technology Conference (AC \& T'09) (pp. 16-25). School of Computing, Information Technology and Engineering, University of East London, UK.
Billiets, M., van der Graaf, E., Loutas, N., van Overeem, A., Passas, A., Peristeras, V., Tarabanis, K., Tsekos, Th., \& Witters, J. (2006). D2.2 - Legislative, institutional and EU policy related requirements. IST STREP PROJECT (SemanticGov).

Elnaghi, M., Elliman, T., AlShawi, S., Aziz, W., \& Kamal, M. (2008). The motivations for change towards a single channel transformational government at Dubai municipality level. Proceedings of eGovernment Workshop '08 (eGOV08). Brunel University, London, UK.

European Commission (2011). E-government in the European Union. E-government factsheets, edition 4.0, December 2011. Retrieved March 30, 2012, from http://www.epractice.eu/

Gascó, M., \& Jiménez, C. E. (2008). Egovernment and organizational IT adoption: The case of the Barcelona city council. Information technology usage and local governance transformations: perspectives from Europe and Latin America, Hull Business School, UK.

Grau, G., Franch, X., \& Maiden, A. M. N. (2008). PRiM: An i*-based process reengineering method for information systems specification. Information and Software Technology, 50, 76-100.

Irani, Z., \& Elliman, T. (2007). Electronic transformation of government in the UK: A research agenda. A Project VIEGO report, ISEing, Brunel University. Retrieved August, 10, 2007, from http://www.iseing.org/iseing/ Resources/VIEGO\%20Report.pdf

Irani, Z., Elliman, T. \& Jackson, P. (2007). Electronic transformation of government in the UK: A Research Agenda. European Journal of Information Systems, 16, 327-335. 
Kolsaker, A., \& Lee-Kelley, L. (2009). Singing from the same hymn sheet? The impact of internal stakeholders on the development of e-democracy. Electronic Journal of e-Government, 7(2), 155 - 162.

London Borough of Havering (2008). Corporate asset management plan 2008/2009. Retrieved May, 3, 2009, from http://www. havering.gov.uk/CHttpHandler.ashx?id=14663 $\underline{\& p=0}$

Milliard, J. (2010). Government 1.5 - Is the bottle half full or half empty? European Journal of ePractice, 9(3). Retrieved January 26, 2011 from www.epractice.eu/files/ European Journal epractice/Volume 9.3_1.pdf

Mousavi S. A. A., Pimenidis, E., \& Jahankhani H. (2007). Challenges to e-municipality in the developing countries. Proceedings of the First International Conference on Electronic Municipality (pp. 172-179). Tehran, Iran.

Mousavi S. A. A., Pimenidis E., \& Jahankhani H. (2007). e-Business models for use in egovernment for developing countries. Proceedings of the $7^{\text {th }}$ European Conference on e-Government (pp. 359-366). Haagse Hogeschool, Den Haag, The Netherlands.

Pimenidis, E., Georgiadis, C. K., Bako, P., \& Zorkadis, V. (2008). Web services security Implementation and evaluation issues. Proceedings of the $4^{\text {th }}$ International Conference on Global e-Security (ICGeSO8), (pp. 299-308). University of East London, London, UK.
Pimenidis, E., Sideridis, A. B., \& Antonopoulou, E. (2009). Mobile devices and services: Bridging the digital divide in rural areas. International Journal of Electronic Security and Digital Forensics (IJESDF), 2(4), 424-434.

Pimenidis, E., Iliadis, L. S,. \& Georgiadis, C. K., (2011). Can e-government systems bridge the digital divide? Proceedings of the 5th European Conference on Information Management and Evaluation (ECIME 2011), (pp. 403-411). Dipartimento di Informatica e Comunicazione, Università dell'Insubria, Como, Italy.

Savvas, I., Pimenidis, E., \& Sideridis, A. (2007). Proposing a high-level requirements mapping framework for testing implementation compatibility in e-government projects. Proceedings of the $7^{\text {th }}$ European Conference on e-Government (pp. 459-468). Haagse Hogeschool, Den Haag, The Netherlands.

Sideridis, A. B., Pimenidis, E., Protopappas, L., \& Koukouli, M. (2011). An evaluation of the initiatives and the progress made on egovernment services in the EU. Proceedings of the Joint Conferences 7th International Conference in Global Security, Safety and Sustainability and 4th e-Democracy (pp. 263270). LNICST Springer, University of Macedonia, Thessaloniki, Greece. 